\title{
ANÁLISE ESPACIAL DO ICMS ECOLÓGICO E SUAS RELAÇÕES COM O DESENVOLVIMENTO SOCIOECONÔMICO DOS MUNICÍPIOS MINEIROS
}

\section{SPATIAL ANALYSIS OF THE ECOLOGICAL ICMS AND ITS RELATIONS WITH THE SOCIOECONOMIC DEVELOPMENT OF MINAS GERAIS' MUNICIPALITIES}

\author{
http://dx.doi.org/10.21714/2179-8834/2018v23n4p15-41
}

Larissa de Albuquerque Sgarbi

Universidade Federal de Viçosa (UFV) - Campus de Rio Paranaíba, Brasil.

E-mail: larissaasgarbi@gmail.com

Rosiane Maria Lima Gonçalves

Universidade Federal de Viçosa (UFV) - Campus de Rio Paranaíba, Brasil.

E-mail: rosianemlg@gmail.com

Luiz Antônio Abrantes

Universidade Federal de Viçosa (UFV), Brasil.

E-mail: abrantes@ufv.br

Antônio Carlos Brunozi Júnior

Universidade Federal de Lavras (UFLA), Brasil.

E-mail: acbrunozi@yahoo.com.br

Submissão: 08 Mar. 2017 Publicação: 30 Mai. 2019. Sistema de avaliação: Double blind review. Centro Universitário UNA, Belo Horizonte - MG, Brasil. Editor geral: Prof. Dr. Gustavo Quiroga Souki

Este artigo encontra-se disponível nos seguintes endereços eletrônicos:

http://revistas.una.br/index.php/reuna/article/view/893

http://dx.doi.org/10.21714/2179-8834/2018v23n4p15-41

\section{Resumo}

O ICMS Ecológico (ICMS-E) é um dos critérios de distribuição da cota parte do ICMS, como recurso adicional, aos Municípios, que atendam ao subcritério unidade de conservação. Assim, além da distribuição de recursos considerando o Valor Adicional Fiscal - VAF, o ICMS-E, em Minas Gerais, compõe o elenco de mais dez critérios, que objetivam corrigir o viés relacionado a desconcentração da renda, atendimento as regiões mais pobres, investimentos na área social, dentre outros. Diante deste contexto uma questão é levantada: O repasse do ICMS_E implicou em mudanças nos indicadores de desenvolvimento socioeconômico dos municípios mineiros? Dessa forma, este estudo analisou a distribuição espacial dos repasses financeiros do ICMS-E e suas implicações no Índice Mineiro de Responsabilidade Social - IMRS e no Produto Interno Bruto (PIB) per capita. Como aspectos metodológicos, dado o efeito spillover entre as decisões de gestores de municípios vizinhos, foi utilizada a análise exploratória de dados espaciais (AEDE), considerando variáveis de repasses do ICMS-E para os municípios, IMRS e PIB per capita nos períodos de 2004 a 2012. Os resultados indicaram ampliação no número de municípios atendidos pelo critério e semelhança de arrecadação entre os municípios espacialmente vizinhos. A análise bivariada indicou que nos anos de 2010 e 2012 municípios com IMRS mais elevados possuíam em sua circunvizinhança municípios com maiores repasses de ICMS-E. Apurou-se baixa e decrescente correlação, ao longo do tempo, ao ser avaliada a relação com o PIB per capita, refletindo o perfil redistributivo do imposto. 
Palavras-chave: Transferências Intergovernamentais fiscais. ICMS Ecológico. Desenvolvimento Socioeconômico.

\begin{abstract}
The Ecological ICMS (ICMS-E) is one of the criteria for the distribution of the share of the ICMS, as an additional resource, to the Municipalities that meet the conservation unit subcriterion. Thus, in Minas Gerais, in addition to the distribution of resources considering the Additional Fiscal Value - VAF, the ICMS-E composes the list of ten other criteria, which aim to correct the bias related to income deconcentration, service to the poorest regions, investments in the social area, among others. Therefore, a question is raised: did the transfer of the ICMS_E implied changes in the indicators of socioeconomic development of the municipalities of Minas Gerais? Thus, this study analyzed the spatial distribution of the financial transfers of the ICMS-E and its effects on the MRS Index of Social Responsibility (IMRS) and the per capita Gross Domestic Product (GDP). Regarding the methodological aspects, considering the spillover effect among the decisions of managers of neighboring municipalities, the exploratory analysis of spatial data (AEDE) was employed, considering the variables of ICMS transfer for municipalities, IMRS and per capita GDP, from 2004 to 2012. The results indicated an increased number of municipalities benefited by the criterion and a similar collection among the spatially neighboring municipalities. The bivariate analysis indicated that, in 2010 and 2012, municipalities with higher IMRS had neighboring municipalities with higher ICMS-E transfers. Low and decreasing correlation was verified, over time, when the relation with per capita GDP was assessed, which reflects the redistributive profile of the tax.
\end{abstract}

Keywords: Intergovernmental fiscal transfers. Ecological ICMS. Socioeconomic Development.

\title{
1. Introdução
}

A preservação ambiental e sua relação com a qualidade de vida da população tem sido amplamente discutida ao longo dos anos em diversos níveis governamentais e dentro da sociedade civil. Seu fortalecimento ocorreu na década de $1970 \mathrm{com}$ a instituição do Clube de Roma. Em 1972, foi realizada a primeira conferência mundial sobre o homem e o meio ambiente pela Assembleia Geral das Organizações das Nações Unidas - ONU, conhecida como Conferência de Estocolmo. Esta conferência teve um importante papel de conscientizar e alertar os Estados e a população sobre as consequências do crescimento vertiginoso e descontrolado da população e, principalmente, a preocupação com as futuras gerações em relação aos efeitos da degradação ambiental, entre outras questões (LIMA, 2012; DUARTE, 2004; BORGES; TACHIBANA, 2005).

O Brasil, influenciado pela Conferência de Estocolmo, acompanhou a tendência mundial de maior conscientização ecológica e de intensificação do processo legislativo na busca de proteção e preservação do meio ambiente nas décadas de 1970 e 1980 (PASSOS, 2009). A Constituição Federal de 1988 (CF/88) tratou amplamente da questão ambiental, sendo considerada por muitos como a "Constituição Verde". Ela incluiu o meio ambiente entre os bens tutelados pelo RELINA, Belo Horizonte - MG, Brasil, v.23, n.4, p.15-41, Dut. - Dez. 2018 - ISSN 2179-8834 
ordenamento jurídico, sistematizou a matéria ambiental, estabeleceu o direito ao meio ambiente sadio como um direito fundamental do indivíduo e instituiu, no art. 170, a proteção do meio ambiente como princípio da ordem econômica (BRASIL, 1988).

O Estado visando assegurar os direitos constitucionais referentes ao meio ambiente, com envolvimento dos entes federados, utilizou a política tributária, através da extrafiscalidade do tributo e das transferências fiscais, como um dos mecanismos para a conciliação do desenvolvimento econômico e da preservação dos recursos ambientais.

A característica extrafiscal do tributo é utilizada para substituir o emprego de multas e punições por incentivos e benefícios fiscais que induzam os agentes econômicos a adotarem mecanismos de produção menos poluidores e os agentes públicos a buscarem um ambiente de qualidade para a sociedade (BRANDÃO, 2013).

Segundo Ring (2008), exceto nos casos onde há potencial para explorar o turismo ecológico, para a maior parte dos municípios as áreas protegidas reduzem as opções para gerar renda local. Assim, as transferências fiscais intergovernamentais de níveis mais centralizados para o nível local, fazem com que o "valor agregado" de bens e serviços ecológicos locais seja reconhecido socialmente. Uma vez que contribuem para a capacidade econômica do município, podem atuar como meio de incentivar os agentes públicos locais a ampliarem seu engajamento com as atividades de conservação, visando à sustentabilidade de longo prazo. O ICMS Ecológico (ICMS-E) aborda este problema repassando recursos aos municípios com base em indicadores de desempenho ambiental.

O Imposto sobre Operações relativas à Circulação de Mercadorias e sobre Prestações de Serviços de Transporte Interestadual e Intermunicipal e de Comunicação - ICMS é a principal receita tributária dos estados e importante fonte de renda para os municípios. Há prerrogativas legislativas que outorgam o repasse de $25 \%$ do ICMS para os municípios, sendo $3 / 4$ conforme o Valor Adicionado Fiscal VAF e o restante segundo legislações específicas dos Estados (parcela com características extrafiscal).

A distribuição pelo VAF não favoreceu a arrecadação de municípios com grandes áreas de preservação ou com ações voltadas para as políticas ambientes. Diante disso, diversos Estados introduziram o critério "meio ambiente" no cálculo da cotaparte do ICMS dos Municípios (incluído no $1 / 4$ dos $25 \%$ destinados aos municípios). Paraná (1991), São Paulo (1993) e Minas Gerais (1995) foram os primeiros estados a adotar o ICMS-E, o qual surgiu como um mecanismo para incentivar e estimular os municípios a desenvolverem programas e projetos voltados para a preservação ambiental (FUNDAÇÃO JOÃO PINHEIRO, 2010; THE NATURE CONSERVANCY, 2015).

O ICMS-E em Minas Gerais foi criado pela Lei $n^{\circ} 12.040$, de 28 de dezembro de 1995, também denominada de Lei Robin Hood, sendo alterada ao longo dos anos até a publicação da Lei 18.030 de 12 de janeiro de 2009, em vigor desde 2010. O cumprimento pleno do critério "Meio Ambiente" representa o repasse de 1,1\% dos $25 \%$ destinados aos municípios. A cota ambiental é dividida da seguinte forma: $45,45 \%$ referem-se a sistemas de tratamento ou disposição final de lixo ou de esgoto sanitário; 45,45\% referem-se ao Índice de Conservação dos Municípios, que considera em seu cálculo as unidades de conservação estaduais, federais, municipais e particulares e área de reserva indígena, e 9,1\% baseiam-se na relação 
percentual entre a área de ocorrência de mata seca em cada Município e sua área total (FUNDAÇÃO JOÃO PINHEIRO, 2010).

Conforme Fernandes et al. (2011) e Euclydes (2013), o percentual de ICMS-E destinado aos municípios mineiros é baixo, o que pode comprometer a capacidade de melhoria das condições ambientais. Assim, analisar se com o passar dos anos os municípios procuraram se adequar ao critério ambiental, ampliando o número de municípios recebedores das transferências, bem como se essa política tributária se traduziu em melhores condições sociais para a população desses municípios, contribui para avaliação de sua efetividade. Além disso, uma vez que a partir da sua função extrafiscal, o ICMS-E desencoraja as práticas ambientalmente incorretas, sem inibir os avanços tecnológicos e a produção industrial, faz-se necessário avaliar sua relação com medidas de atividade econômica dos municípios.

Diante do exposto uma questão é levantada: O repasse do ICMS_E implicou em mudanças nos indicadores de desenvolvimento socioeconômico dos municípios mineiros? Dessa forma, este estudo analisou a distribuição espacial dos repasses financeiros do ICMS-E e suas implicações no Índice Mineiro de Responsabilidade Social - IMRS e no Produto Interno Bruto (PIB) per capita.

A análise espacial será utilizada uma vez que conforme Case, Rosen e Hines (1993), há um efeito spillover entre administrações públicas vizinhas, não sendo as decisões de seus gestores tomadas de maneira isolada, e sim de maneira interdependente.

Este estudo se justifica pela adição de novo foco ao tema, considerando que pesquisas anteriores, em sua maioria, abordaram a relação entre as transferências e a ampliação das áreas de preservação. Com abordagem diferenciada, destaca-se o trabalho de Da Silva Júnior e Sobral (2014) que avaliou, por meio de uma simulação de cadeia de Markov, a eficácia do ICMS socioambiental em relação aos componentes socioeconômicos (educação, saúde e receita tributária própria), no período 2004 a 2009, para o estado de Pernambuco. Os resultados demonstraram a importância da polícia em criar uma saudável competição por recursos entre os municípios do Estado, sendo um importante instrumento para melhorar a eficiência da gestão municipal.

Além disso, destaca-se sua relevância considerando que o Brasil é um país amplo territorialmente, e com isso, existem diversas políticas tributárias que incentivam a repartição de receitas entre os entes da Federação (Federalismo). No entanto, são questionáveis suas efetividades. O estado de Minas Gerais possui heterogeneidade em suas regiões. Assim, analisar políticas equitativas financeiras contribui para a agenda do setor público. Apesar de existirem outros trabalhos sobre a Lei $n^{\circ}$ 12.040, de 28 de dezembro de 1995, pouco se discutiu sobre a distribuição espacial e seus efeitos sobre o desenvolvimento.

As contribuições são válidas para a ciência de diferentes formas. Na área acadêmica, ampliam-se os estudos sobre um importante mecanismo utilizado pelo Estado para proteção ao meio ambiente, o ICMS-E. O estudo adicionou percepções sobre os agrupamentos das regiões mineiras que recebem os repasses do ICMS-E e sua relação com índices de desenvolvimento e Produto Interno Bruto. Além disso, destaca-se o uso da análise espacial, técnica pouco explorada em pesquisas nas áreas de Ciências Sociais Aplicadas.. 


\section{Referencial Teórico}

\subsection{Políticas Fiscal e a Extrafiscalidade dos Tributos}

A política fiscal configura-se como uma estratégia da política econômica de aplicar medidas que promovam o direcionamento dos acontecimentos econômicos que, uma vez sem ela, tomariam outros rumos. Um mecanismo de concretização dessa política é a tributação (IVERSEN,1955).

O Sistema Tributário decorre de decisões de cunho político, mas não pode, entretanto, ser livremente formulado ou executado pelas autoridades governamentais. Para elaboração de um sistema justo e efetivo, devem-se respeitar os limites legais à atuação do Estado. Além disso, é importante não impor medidas que desconsiderem as expectativas da população em ter uma economia equilibrada, nem extrapolar os princípios firmados na Constituição Federal (LOBO,2003).

A política tributária, entendida no âmbito da política fiscal, refere-se não somente aos atos de tributação destinados a fins arrecadatórios - finalidade fiscal dos tributos - mas principalmente àqueles atos de tributação cujos efeitos visados são percebidos em outros âmbitos, atendendo aos objetivos econômicos previamente estabelecidos e elencados como prioritários na política fiscal adotada no país. São esses os atos de tributação extrafiscais (LOBO, 2003).

A finalidade fiscal dos tributos é dividida em dois grandes grupos: o primeiro compreende os tributos que visam alimentar o caixa geral do Estado, sem definição da destinação dos recursos, podendo ser utilizados em qualquer despesa orçamentária. O outro grupo é o dos tributos que possuem destinação específica, em que os recursos arrecadados pela tributação possuem a função de financiar despesas pré-determinadas do Estado (HACK, 2012).

Por outro lado, a tributação extrafiscal possui finalidade precípua diversa da arrecadação, uma vez que direcionam comportamentos, por meio de uma tributação progressiva ou regressiva, ou da concessão de benefícios e incentivos fiscais. Percebe-se que a simples característica de destinação específica dos tributos não é suficiente para classificá-los como extrafiscais, uma vez que a finalidade principal é a arrecadação e não um efeito social, político ou econômico a partir do estímulo - ou desencorajamento - de condutas (BALLEIRO, 2010; HACK, 2012).

A característica fiscal dos tributos predominou até o fim do século $X I X$, período no qual prevalecia a doutrina político-econômica do liberalismo. O Estado mínimo necessitava apenas dos tributos que possuíam uma finalidade fiscal clássica: a de prover, sem finalidade específica, os recursos necessários para a manutenção da máquina estatal e de suas atividades. Tal cobrança sem visar o alcance de outras finalidades - sociais, políticas ou econômicas - além da arrecadação, caracterizou o Estado Fiscal Liberal (TORRES, 1991).

A partir do século XX, com a evolução do Estado, abandonou-se a concepção unicamente liberal, incluindo-se uma concepção social que constituía o Estado Fiscal Social. Nessa, o Estado tornou-se mais intervencionista, direcionando seus gastos para além da exclusiva manutenção da máquina pública, passando a promover os serviços públicos essenciais. Assim, ganharam protagonismo os tributos com função de financiar atividades específicas do Estado e, portanto, obter efeitos prédeterminados (NABAIS, 2007). 
Os objetivos da política tributária extrapolam a simples arrecadação de recursos ao erário com ou sem destinação específica. O Estado utiliza-se da prerrogativa de intervenção sobre a economia para induzir comportamentos desejáveis a partir da criação de facilidades e economicidades para aquelas condutas preferidas e, de outro lado, na criação de obstáculos, dificuldades e custos mais altos para as práticas indesejáveis. É importante ressaltar que a extrafiscalidade não tem a função de proibir comportamentos, mas criar vantagens para que o particular opte por agir conforme os princípios defendidos pelo Estado (HACK, 2012; SCHOUERI, 2005).

Tal função extrafiscal do tributo é exemplificada, no âmbito da tributação ambiental, pelo ICMS-E. Este método de repartição de receitas tributárias surgiu como alternativa para os estados coibirem práticas predatórias, sem suprimir e coibir avanços tecnológicos e a produção industrial. Tal metodologia oficializou a necessidade de o arcabouço do desenvolvimento envolver, além da variável econômica, a social e a ambiental.

\subsection{Transferências Fiscais Ecológicas}

A importância das transferências fiscais ecológicas se dá pelo fato de que regiões com maiores áreas de preservação têm também maiores despesas para cuidar desse bem, assim como a capacidade fiscal é diferente entre as regiões (KOLLNER; SCHELSKE; SEID, 2002).

O federalismo ambiental faz com que a provisão de bens e serviços ecológicos por meio da descentralização deva ser atribuída a níveis mais baixos de governo. No entanto, a execução desta regra exige uma abordagem diferenciada. Os benefícios da preservação ambiental não se limitam à população local, possuindo externalidades. As transferências fiscais de níveis mais centralizados para o nível local fazem com que os municípios sejam compensados pelos benefícios externos de suas despesas de conservação, bem como pelos custos de oportunidade relacionados às restrições de uso da terra (RING, 2008).

De acordo com Sauquet, Marchand e Féres (2014), as transferências fiscais ecológicas constituem um instrumento de conservação relativamente recente, inovador e pouco estudado, sendo o ICMS-E implementado no Brasil o primeiro mecanismo desse tipo a ser criado. Conforme May et al. (2002), o ICMS-E tem sido amplamente elogiado por recompensar governos locais pelo seu comprometimento com a preservação do meio ambiente.

Diversos estados brasileiros, no intuito de incentivar os municípios a se comprometerem com a preservação do meio ambiente, introduziram o critério "Meio Ambiente" no cálculo da cota-parte do ICMS dos municípios, dando origem ao ICMS-E, sendo Minas Gerais o terceiro estado a adotar esse critério (FUNDAÇÃO JOÃO PINHEIRO, 2010).

Segundo Veiga Neto (2000), no estado de Minas Gerais, assim como no Paraná, o ICMS-E originou-se em decorrência de reivindicações de municípios que se consideravam em desvantagem comparativa, uma vez que possuíam grandes áreas protegidas em sua extensão territorial. Esse movimento foi realizado pelos prefeitos dos municípios que faziam parte do Parque Estadual do Rio Doce, 
localizado no leste do estado na região do Vale do Aço. A junção das diversas forças que defendiam o ICMS-E culminou no ano de 1995, na incorporação do critério ambiental entre os critérios de distribuição do ICMS.

Ressalta-se que o ICMS-E não é um novo imposto, mas sim uma inovação em relação ao método empregado na repartição das receitas arrecadadas do ICMS. Neste sentido, a sua adoção não gera qualquer ônus financeiro para o Estado ou aumento da carga tributária dos contribuintes, havendo apenas a adoção de novos critérios para a repartição da renda (SCAFF; TUPIASSU, 2004).

O ICMS-E se constituiu como uma ação de regulação não coercitiva do Estado. Isso ocorre por meio da introdução das metodologias ainda não amplamente difundidas dos princípios da prevenção e compensação, nas quais o Estado estimula os Municípios a zelarem pelo meio ambiente ao invés de instituir ações corretivas de aplicação de repressões, punições e sanções, amparadas pelo princípio poluidorpagador (ARAÚJO, 2005; MOTTA; OLIVEIRA; MARGUILES, 2000; SCAFF; TUPIASSU, 2005).

De acordo com Droste, May e Ring (2017), as transferências fiscais ecológicas passaram ao longo dos últimos anos a receberem atenção também fora do Brasil, enumerando os seguintes trabalhos: Santos et al., (2012), com o estabelecimento por Portugal em 2007 de transferências fiscais ecológicas municipais; Borie et al., (2014), que tratou da compensação para municípios na França referentes a áreas de parques; Hajkowicz (2007),que utilizou uma análise multicritérios para alocação de fundos ambientais por meio de transferências fiscal em Queensland, Austrália; além de outros trabalhos referentes à Alemanha, Suíça, Indonésia e Índia, (Czybulka e Luttmann, 2005; Irawan et al., 2014; Köllner et al., 2002; Kumarand Managi, 2009; Mumbunan, 2011; Perner e Thöne, 2007; Ring, 2002, 2008; Schröter-Schlaack et al., 2014).

Estudos em relação ao ICMS-E no Brasil têm sido realizados, analisando a importância desse tributo para ampliação de áreas de preservação. Droste, May e Ring (2017) analisaram, por meio de dados em painel, o ICMS-E em 17 estados brasileiros, no período de 1991 a 2009. Os resultados da pesquisa indicaram que a introdução do subcritério ambiental na repartição do ICMS proporcionou aos municípios, que receberam esses repasses, o aumento das áreas de preservação. Isso sinaliza um efeito descentralizante para a conservação da natureza, demonstrando a importância das transferências para as políticas públicas de preservação do meio ambiente e como meio de suprir os orçamentos restritos dos municípios.

Euclydes (2013) discutiu aspectos do ICMS-E, repassado pelo Estado, da Compensação Financeira pela Exploração de Recursos Minerais (CFEM) recebida da União e da criação de Unidades de Conservação (UCs) no estado de Minas Gerais, a partir de multicasos de municípios situados no Quadrilátero Ferrífero. Os resultados evidenciaram que o ICMS-E tem sido de pouca eficiência no incentivo à criação, à ampliação de áreas de proteção e ao empenho na qualidade da conservação ambiental nos municípios mineradores do estado. Esse resultado pode ser justificado pela reduzida expressividade do subcritério "unidades de conservação" do ICMS-E mineiro, já que muitos municípios recebem mais pela atividade mineradora que realizavam na década de 1980 que pela proteção ambiental que se dá em seus territórios. Assim, para os municípios analisados, o 
ICMS não representou um incentivo relevante para a proteção ambiental, o que se confirmou nos casos dos maiores arrecadadores de CFEM, que pouco investiram na criação de áreas protegidas municipais ou na manutenção das UCs criadas pelo estado.

Fernandes et al. (2011) utilizaram um modelo de dados em painel para verificar qual a relação entre a área protegida e o valor do ICMS-E em Minas Gerais, no período de análise de 1997 a 2007. Os autores encontraram relação direta entre o montante recebido e o crescimento de áreas protegidas nos municípios mineiros.

Resultados semelhantes foram encontrados por May et al. (2002), que analisaram as consequências e a efetividade do ICMS-E nos estados do Paraná e de Minas Gerais e por Loureiro (1997) mediante a análise da evolução do número e da superfície das unidades de conservação registradas para efeito de crédito do ICMS-E nos municípios paranaenses.

Por sua vez, Sauquet, Marchand e Féres (2014) realizaram uma análise, por meio de um modelo Tobit espacial bayesiano, dos efeitos do ICMS-E para o estado do Paraná, no período de 2000 a 2010. O comportamento dos municípios vizinhos do estado do Paraná não teve efeito sobre a propensão de um município criar unidades de conservação municipal. Foi observada uma substituição estratégica entre as decisões de conservação, e não complementaridade, ou seja, o ganho de utilidade obtido com a criação de uma área de preservação diminuía (ou aumentava) se um vizinho criasse mais (ou menos) áreas protegidas, o que faz com que o resultado esperado final do ICMS-E fique comprometido. Essas interações negativas podem ser um obstáculo para a criação de um corredor de biodiversidade, causando ainda mais fragmentação da floresta no estado do Paraná.

Em suma, percebeu-se que há pesquisas que evidenciam a relevância do ICMS-E em territórios nacionais. Esta base de literatura apresentada dá sustentação a este estudo, garantindo sua importância para os temas de transferências fiscais e desenvolvimento econômico-social.

\section{Procedimentos Metodológicos}

\subsection{Dados do Estudo}

A população deste estudo refere-se aos 853 municípios mineiros, que foram agrupados segundo as dez regiões administrativas do Estado, sendo: Alto Paranaíba (31 municípios); Central (158 municípios); Centro-Oeste de Minas (56 municípios); Jequitinhonha/Mucuri (66 municípios); Zona da Mata (142 municípios); Noroeste de Minas (19 municípios); Norte de Minas (89 municípios); Rio Doce (102 municípios); Sul de Minas (155 municípios) e Triângulo Mineiro (35 municípios).

Os dados secundários foram coletados em diversas bases, sendo: i) para as informações do ICMS-E, utilizou-se os dados da Fundação João Pinheiro - FJP, da Secretaria de Estado de Fazenda de Minas Gerais - SEF/MG e da Secretaria de Estado de Meio Ambiente e Desenvolvimento Sustentável de Minas Gerais SEMAD; ii) para os dados referentes ao Produto Interno Bruto per capita (PIB) dos municípios, utilizou-se o banco de dados da SEF/MG, Instituto Brasileiro de Geografia e Estatística - IBGE, Coordenação de Contas Nacionais - Conac e Centro 
de Estatística e Informações - CEI da FJP, e iii)para os dados referentes ao Índice Mineiro de Responsabilidade Social (IMRS), houve a coleta junto à Fundação João Pinheiro -FJP, entidade responsável pela sua publicação.

As informações foram bienais, coletadas de 2004 a 2012, devido às restrições de dados quanto ao IMRS.

\subsection{Considerações Analíticas}

Para atingir os objetivos deste estudo, foi realizada a aplicação da análise exploratória de dados espaciais, que favoreceu o entendimento das influências do ICMS-E. Além disso, inicialmente, houve a utilização de análises descritivas para o conhecimento dos comportamentos dos dados utilizados nesta pesquisa.

\subsubsection{Análise Exploratória de Dados Espaciais}

A Análise Exploratória de Dados Espaciais - AEDE consiste em um conjunto de técnicas utilizadas na análise dos efeitos advindos da dependência espacial e da heterogeneidade espacial a partir do esboço de padrões de correlação espacial, ocorrência de clusters ou outliers (ALMEIDA, 2012; ANSELIN, 1998).

Por meio dessa técnica é possível descrever e visualizar distribuições espaciais, identificar localidades espaciais atípicas, descobrir padrões de associação espacial e sugerir diferentes regimes espaciais (PEROBELLI et al., 2007).

Ocorre autocorrelação espacial quando o valor de uma dada variável numa região está relacionado com o valor da mesma variável em uma região vizinha. A heterogeneidade espacial ocorre quando os dados de regiões vizinhas não se relacionam (ANSELIN, 1988).

Para iniciar a AEDE deve-se, primeiramente, testar a hipótese de que os dados espaciais sejam distribuídos aleatoriamente considerando que os valores apresentados para uma região não dependam dos valores do mesmo atributo em regiões vizinhas (ALMEIDA, 2012; ANSELIN, 1988).

Concluída esta etapa, utilizou-se a AEDE para identificar medidas de autocorrelação espacial global e local, investigando-se a influência dos efeitos espaciais por meio de métodos quantitativos, definindo-se, primeiramente, uma matriz de pesos espaciais a fim de se determinar o grau de interação entre as regiões (PEROBELLI et. al.2007).

Além dessa matriz, a estatística global do indicador de Moran univariado, o diagrama de dispersão de Moran univariado, a estatística global do indicador de Moran bivariado, o diagrama de dispersão de Moran bivariado e a estatística local do indicador de Moran bivariado também foram utilizados (Quadro 1). 
Quadro 1 - Testes aplicados na pesquisa para a AEDE

\begin{tabular}{|c|c|}
\hline Testes & Aplicabilidades \\
\hline $\begin{array}{l}\text { Matriz de Pesos } \\
\text { Espaciais }\end{array}$ & $\begin{array}{l}\text { É utilizada para representar a maneira de um fato apresentado na } \\
\text { vizinhança influenciar o mesmo na unidade observacional específica. } \\
\text { Expressa a estrutura espacial dos dados (LeSAGE, 2009) }\end{array}$ \\
\hline $\begin{array}{l}\text { Box Map/Estatística } \\
\text { global do Indicador de } \\
\text { Moran univariada }\end{array}$ & $\begin{array}{l}\text { Este indicador, fornece o i) Nível de Significância para dados } \\
\text { distribuídos aleatoriamente ou correlacionados; ii) Indicador de } \\
\text { Moran positivo e significativo indica dados concentrados, e iii) } \\
\text { Magnitude do Índice: indica a força da autocorrelação espacial. Quanto } \\
\text { mais próximo de 1, mais forte é a autocorrelação e quanto mais próximo } \\
\text { de -1, mais dispersos estão os dados (ALMEIDA, 2012). }\end{array}$ \\
\hline $\begin{array}{l}\text { Diagrama de Dispersão } \\
\text { de Moran univariado }\end{array}$ & $\begin{array}{l}\text { É utilizado para a visualização da autocorrelação espacial. O diagrama } \\
\text { mostra além da medida global de associação linear espacial, a } \\
\text { associação espacial entre as regiões e seus vizinhos em quatro } \\
\text { quadrantes (ALMEIDA, 2012). }\end{array}$ \\
\hline $\begin{array}{l}\text { Estatística global do } \\
\text { Indicador de Moran } \\
\text { bivariada }\end{array}$ & $\begin{array}{l}\text { Uma vez se tratando da versão bivariada da estatística global do } \\
\text { Indicador de Moran, o numerador refere-se a uma medida de } \\
\text { covariância (produto cruzado) e o denominador representa um } \\
\text { reescalonamento a partir da variância de dados (MARCONATO, 2015). } \\
\text { Por meio da utilização dessa estatística, é possível obter uma indicação } \\
\text { do grau de associação linear (positiva ou negativa) entre o valor para } \\
\text { uma variável em uma dada região e a média de outra variável nos locais } \\
\text { vizinhos (ANSELIN; SYABRI; KHO, 2003). }\end{array}$ \\
\hline $\begin{array}{c}\text { Diagrama de dispersão } \\
\text { de Moran bivariado }\end{array}$ & $\begin{array}{l}\text { O diagrama de Moran bivariado é representado por um gráfico de duas } \\
\text { variáveis, na qual o coeficiente da inclinação da curva de regressão é } \\
\text { dado pela estatística I de Moran (ALMEIDA et al. 2005). Mediante a } \\
\text { análise, é possível verificar a relação linear entre duas variáveis a partir } \\
\text { da análise da distribuição em quatro associações espaciais: alto-alto - } \\
\text { AA; baixo-baixo - BB; alto-baixo - AB e baixo-alto - BA. }\end{array}$ \\
\hline $\begin{array}{l}\text { Estatística local do } \\
\text { Indicador de Moran } \\
\text { bivariada }\end{array}$ & $\begin{array}{l}\text { O indicador local de associação espacial (LISA) fornece o grau de } \\
\text { autocorrelação espacial estatisticamente significativo, em cada unidade } \\
\text { regional. Da mesma forma, como ocorre para a análise univariada, } \\
\text { combinando-se as informações do diagrama de Moran bivariado com o } \\
\text { mapa LISA de significância, obtém-se o mapa de Cluster com os } \\
\text { regimes bivariados, que permite uma visualização geográfica mais } \\
\text { adequada do grau de concentração das variáveis estudadas } \\
\text { (PIMENTEL; HADDAD, 2004). }\end{array}$ \\
\hline
\end{tabular}

As ações, atividades e conhecimentos gerados são destacados no Quadro 2.

Quadro 2 - Análises e percepções para a pesquisa

\begin{tabular}{|c|l|}
\hline Ações & \multicolumn{1}{|c|}{ Atividades e conhecimentos Gerados } \\
\hline $\begin{array}{c}\text { Agrupar os municípios pelo potencial de } \\
\text { arrecadação do ICMS-E }\end{array}$ & $\begin{array}{l}\text { - Conhecer a evolução do ICMS-E em Minas Gerais; } \\
\text { - Entender e comparar a distribuição do ICMS-E entre os } \\
\text { municípios e regiões de Minas Gerais. }\end{array}$ \\
\hline $\begin{array}{c}\text { Identificar a relação entre o Produto } \\
\text { Interno Bruto per capita e o ICMS-E }\end{array}$ & $\begin{array}{l}\text { - Conhecer as ações realizadas pelos municípios para } \\
\text { atender aos critérios da Lei Robin Hood e sua associação } \\
\text { ou influência no Produto Interno Bruto. }\end{array}$ \\
\hline $\begin{array}{c}\text { Identificar a relação entre o IMRS e o } \\
\text { ICMS-E }\end{array}$ & $\begin{array}{l}\text { - Entender se os municípios com atendimento aos } \\
\text { subcritérios do ICMS-E são aqueles com níveis satisfatórios } \\
\text { de desenvolvimento socioeconômico. }\end{array}$ \\
\hline
\end{tabular}

Para este estudo, na AEDE, foi utilizado o software GeoDaSpace ${ }^{\mathrm{TM}}$. 


\section{Discussão dos resultados}

\subsection{O estado de Minas Gerais e a distribuição do ICMS-E}

O estado de Minas Gerais possui uma população de aproximadamente 20 milhões de habitantes distribuídos em 853 municípios (IBGE, 2015).Destes municípios, ao longo dos anos de 2004 a 2012, 592, aproximadamente 70\%, foram contemplados, ao menos em um ano, com o repasse de ICMS-E. Apenas 307, representando aproximadamente $52 \%$ dos municípios, receberam a cota parte do imposto em todos os anos de estudo.

O crescimento no número de municípios que receberam as transferências entre 2004 (367 municípios) e 2012 (545 municípios) foi de 43,50\%. Este resultado evidencia o efeito incentivador das transferências fiscais, para que o poder público local tenha maior zelo por bens públicos, como o meio ambiente, cuja manutenção é de interesse difuso. Nos quatro últimos anos pesquisados, houve um aumento de 8,89 vezes nos repasses do ICMS-E, provavelmente decorrente da introdução do critério "Mata Seca", pela Lei 18.030/2009, uma vez que foi esta a principal alteração ocorrida nas regras de distribuição deste tributo.

Em relação às regiões de planejamento, observa-se que dos anos de 2004 a 2008 não houve alterações significativas na distribuição de municípios recebedores de ICMS-E, com aumento ao longo desse período de apenas 18 municípios. No entanto, avaliando os anos de 2010 e 2012, percebe-se um adensamento no quantitativo de municípios contemplados, com destaque para a região de planejamento Norte e seus arredores. Isso ratifica a relevância dada à introdução do critério "Mata Seca", uma vez que tal bioma é característico da região Norte (Tabela 1).

Tabela 1 - Evolução do ICMS-E nas mesorregiões do estado de Minas Gerais, no período de 2004 a 2012

\begin{tabular}{|c|c|c|c|c|c|c|}
\hline \multicolumn{7}{|c|}{ Painel A - Evolução de municípios arrecadadores } \\
\hline \multirow{3}{*}{\multicolumn{2}{|c|}{ Número de municípios }} & \multicolumn{5}{|c|}{ Períodos } \\
\hline & & 2004 & 2006 & 2008 & 2010 & 2012 \\
\hline & & 367 & 381 & 385 & 528 & 545 \\
\hline \multicolumn{7}{|c|}{ Painel B - ICMS-E nas regiões de planejamento } \\
\hline Regiões & Número de municípios & \multicolumn{5}{|c|}{ Média de arrecadação, 2004 a 2012} \\
\hline Jequitinhonha/Mucuri & 41 & \multirow{2}{*}{\multicolumn{5}{|c|}{$68.659,93$}} \\
\hline Norte de Minas & 85 & & & & & \\
\hline Sul de Minas & 94 & \multicolumn{5}{|c|}{$\begin{array}{l}84.794,56 \\
85574,49\end{array}$} \\
\hline Zona da Mata & 104 & \multicolumn{5}{|c|}{$89.353,00$} \\
\hline Alto Paranaíba & 19 & \multicolumn{5}{|c|}{$94.840,15$} \\
\hline Central & 120 & \multicolumn{5}{|c|}{$108.019,80$} \\
\hline Centro-Oeste & 36 & \multicolumn{5}{|c|}{$123.192,84$} \\
\hline Rio Doce & 64 & \multicolumn{5}{|c|}{$145.174,94$} \\
\hline Noroeste de Minas & 11 & \multicolumn{5}{|c|}{$175.304,53$} \\
\hline Triângulo Mineiro & 19 & \multicolumn{5}{|c|}{$250.314,66$} \\
\hline
\end{tabular}

Fonte: Dados da pesquisa. 


\subsection{Análise espacial da arrecadação do ICMS-E no estado de Minas Gerais}

A primeira das técnicas utilizadas nesse estudo, para AEDE, foi o Box Map, em que cada objeto é classificado (em quartis) conforme sua posição em relação aos quadrantes do gráfico de espalhamento e recebe uma cor correspondente no mapa gerado. Na Figura 1 é evidenciado o Box Map do quantitativo da variável ecológica (ICMS) em Minas Gerais, para os anos de 2004, 2006, 2008, 2010 e 2012.

Observa-se, a não ocorrência de outliers inferiores e a presença de outliers superiores de repasses em todos os anos analisados. Nota-se que de 2004 a 2012 , a variação na proporção de outliers foi pequena. Em 2004 e 2006, os outliers representavam 6,8\% dos municípios contemplados com o ICMS-E, e em 2008 e 2010 , de $8,8 \%$ e $8,5 \%$, respectivamente. O aumento da quantidade de outliers concentrados em regiões específicas indica o baixo poder redistributivo apresentado pelo ICMS-E ao longo desses anos.

Apesar da proporção de outliers serem semelhantes, observa-se que nos três primeiros anos estudados os repasses de ICMS-E concentraram-se principalmente nas regiões Noroeste de Minas e Triângulo Mineiro. No ano de 2010, observa-se que foram reduzidas as ilhas de concentração nessas regiões e que surgiram algumas na região Norte. Tal situação reflete a introdução do subcritério Mata Seca, que impulsionou a arrecadação dos municípios do Norte de Minas. 


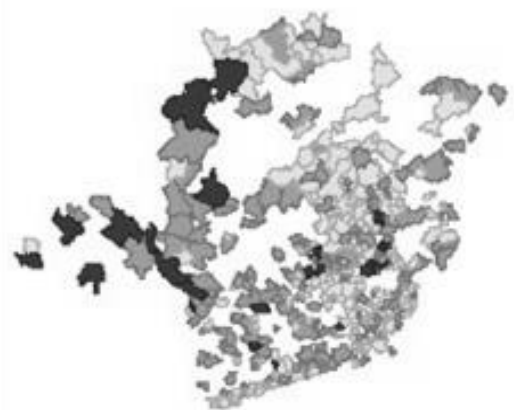

Hinge=1.5: ICMS_2004

$<25 \%(92)$

$25 \%-50 \%(92)$

$50 \%-75 \%(91)$

$>75 \%(67)$

Upper outlier (25)
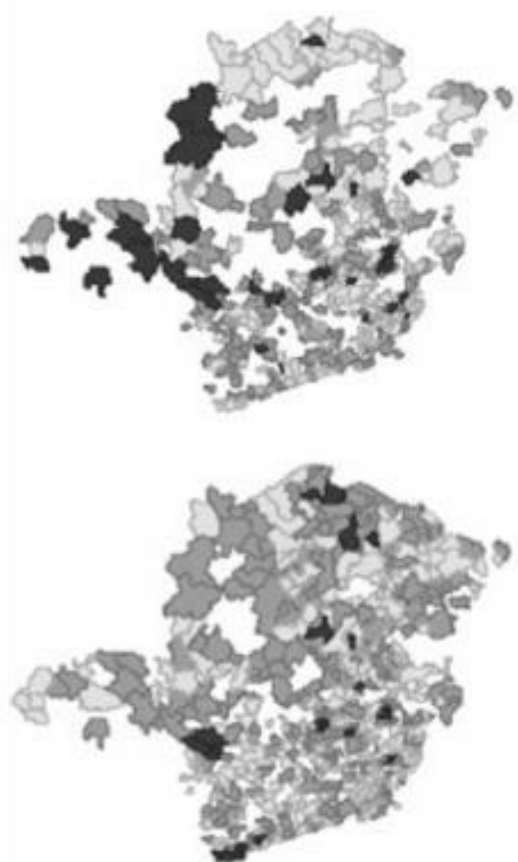

$\square$ Lower outlier $(0)$

$<25 \%(96)$

$25 \%-50 \%(97)$

$50 \%-75 \%(96)$

$>75 \%(62)$

Upper outlier (34)

Hinge= $=1.5$ : ICMS 2012

$\square$ Lower outler (0)

$\square<25 \%(136)$

25\%-50\%(137)

$50 \%-75 \%(136)$

$>75 \%(110)$

Upper outlier (26) $\square$ Lower outlier (0)

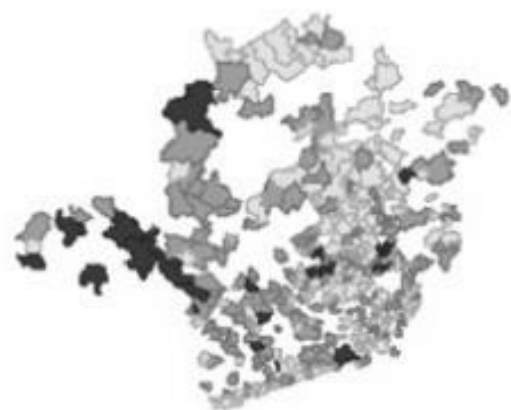

Hinge=1.5: ICMS_2006

$\square$ Lower outlier $(0)$

$<25 \%(95)$

$25 \%-50 \%(96)$

$50 \%-75 \%(95)$

$>75 \%(69)$

Upper outlier (26)

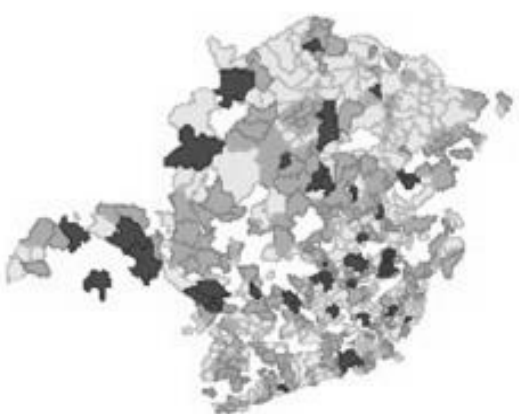

Hinge=1.5: ICMS 2010

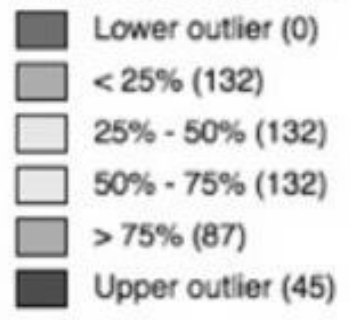

Figura 1 - Box Map da distribuição do ICMS-E em Minas Gerais, de 2004 a 2012. Fonte: Dados da pesquisa. 
Por outro lado, em 2012 constata-se uma redução dos outliers superiores e um aumento de dados nas classes inferiores, representando um recebimento mais uniforme do ICMS-E. Neste ano, os outliers representavam 4,8\% dos municípios contemplados com ICMS-E. Em relação à distribuição geográfica, observa-se uma significativa redução de concentração de repasses nas regiões Noroeste, Triângulo Mineiro e Central, e aumento na região Norte, dando continuidade ao observado no ano de 2010.

Relativamente, a revisão dos critérios ambientais advindo da lei 18.030/2009 promoveu, além de um aumento no número de municípios contemplados com a cota ambiental, uma melhor redistribuição desse repasse.

Avaliando mudanças da distribuição de ICMS-E em Minas Gerais, através dos mapas temáticos, percebe-se a existência, em todos os anos de estudo, de autocorrelação espacial positiva da variável ICMS-E, a um nível de significância de $5 \%$. O sinal positivo da estatística de Moran aponta que os municípios que apresentam valores de ICMS-E elevados estão cercados por unidades municipais que também apresentam montantes acima da média, enquanto as localidades municipais que exibem taxa abaixo da média são circunvizinhadas por municípios com baixa taxa de recolhimento da cota ambiental do ICMS-E.

Do período de 2004 para 2012, houve alteração significativa da associação espacial, passando de 0,0821 para 0,3591. Estes escores indicam que houve aumento de 4,4 vezes da concentração espacial da taxa de arrecadação de ICMS-E ao longo de oito anos.

O Índice de Moran global univariado, apesar de ser um bom instrumento de comportamento espacial, utiliza um único valor como medida de associação. Com o intuito de evidenciar os locais em que a dependência espacial é ainda mais acentuada, utilizou-se o Índice Local de Associação Espacial (LISA) para gerar o mapa de Cluster (aglomerados), conforme Figura 2. 


\section{Reuna}

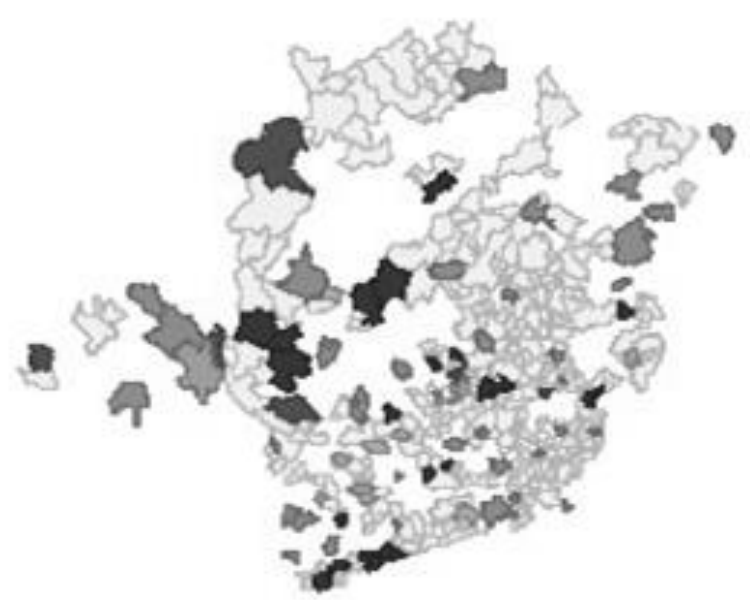

LISA Cluster Map: icms_2004, I_CUS_2004 (99 perm)

$\square$ Not Significant (281)

$\square$ High-High (6)

$\square$ Low-Low (25)

$\square$ Low-High (8)

$\square$ High-Low (9)

$\square$ Neighborless (38)

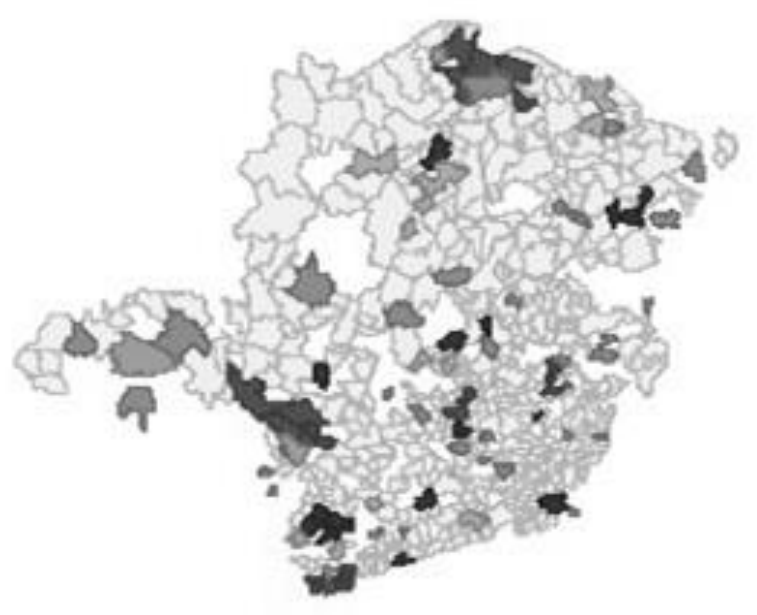

LISA Custer Map: ioms 2012. I ICUS 2012 (99 perm)

$\square$ Not Significant (45s)

W High-High (24)

Low-Low (17)

- Low-High (4)

$\square$ High-Low (12)

Neighberloss (33)

Figura 2 - Mapa de Cluster para o ICMS-E em Minas Gerais, de 2004 e 2012 Fonte: Dados da pesquisa.

REUNA, Belo Horizonte - MG, Brasil, v.23, n.4, p.15-41, Dut. - Dez. 2018 - ISSN 2179-8834 
Para o ano de 2004, percebeu-se que somente 1,6\% dos municípios possuem altos valores arrecadados do ICMS-E (Teste LISA - alto-alto), principalmente nas regiões de planejamento Noroeste, Alto Paranaíba, Triângulo Mineiro e Central. Por outro lado, foram observados muitos padrões, Teste LISA - baixo-baixo, que estão distribuídos por diversas regiões do estado. Tais observações confirmam e evidenciam a existência de autocorrelação espacial positiva para esses padrões, ou seja, aqueles municípios que arrecadam muito ICMS-E estavam cercados por outros que também receberam muito. Contrariamente também se percebeu unidades municipais que arrecadaram pouco cercadas por outras que arrecadaram pouco.

Em 2012, os municípios com correlação positiva alto-alto (Teste LISA) aumentaram para 4,4\%, e a correlação baixo-baixo reduziu de $6,82 \%$ para $3,12 \%$. Observou-se que no período de 2012, as concentrações de novas áreas de padrões alto-alto, principalmente na região Norte, confirmando a relevância do subcritério Mata Seca. O padrão baixo-baixo, indicativo de uma correlação de baixa arrecadação, apesar de menor intensidade, manteve o padrão geográfico de distribuição nas regiões do Jequitinhonha/Mucuri, Rio Doce, Zona da Mata e Sul de Minas.

As mudanças nas distribuições do ICMS-E, de 2004 para 2012, podem ser explicadas, em parte, pelo conhecimento e adaptação dos Municípios à burocracia e às exigências legais, além de poderem usufruir dos benefícios decorrentes desses ajustes, relacionadas às melhorias no saneamento básico ou em áreas de preservação. Além disso, a alteração dos critérios ecológicos favoreceu os efeitos redistributivos da Lei Robin Hood.

\subsection{Repasse de ICMS-E e o IMRS}

Para verificar se Municípios com melhores indicadores sociais apresentavam aumento da arrecadação do ICMS-E ou a ocorrência da situação inversa, utilizou-se da autocorreção global bivariada.

O primeiro teste objetivou identificar se municípios que receberam maiores repasses de ICMS, pelo efeito espacial, eram cercados por municípios com melhor IMRS. Os resultados confirmaram esta ocorrência apenas no ano de 2012. Estes resultados podem ser decorrentes do percentual destinado ao ICMS-E de Minas Gerais, ou seja, $1,1 \%$ frente aos $5 \%$ no estado do Paraná. O trabalho de Fernandes et al. (2011) ressaltou que o valor baixo poderia não motivar os gestores municipais a se adequarem aos critérios.

Com base nos resultados anteriores, outra análise foi conduzida partindo do pressuposto de que municípios com melhores indicadores sociais tenderiam a adotar mais critérios para recebimento do ICMS, ampliando sua cota do ICMS-E, conforme ilustrado na Tabela 2.

Com a utilização de uma matriz de pesos espaciais do tipo Rainha (Queen) e a um nível de significância de 5\%, observa-se que apenas para os anos de 2010 e 2012 pode-se considerar a ocorrência de autocorrelação espacial positiva. 
Tabela 2 - Autocorrelação global bivariada (Moran) entre o IMRS e o ICMS-E, nos períodos de 2006, 2008, 2010 e 2012

\begin{tabular}{l|cc|c}
\hline \multicolumn{1}{c|}{ Variáveis } & I & Z & p-value \\
\hline IMRS e ICMS-E-2006 & 0,0098 & 0,2902 & 0,386 \\
IMRS e ICMS-E-2008 & 0,0302 & 1,0214 & 0,153 \\
IMRS e ICMS-E-2010 & 0,0736 & 2,14 & 0.019 \\
IMRS e ICMS-E-2012 & 0,1307 & 5,0046 & 0,001 \\
\hline
\end{tabular}

Fonte: Dados da pesquisa.

Somente, para 2010 e 2012, foi possível inferir que os municípios com elevado IMRS são cercados por outros contemplados com valores de ICMS-E acima da média. As unidades municipais onde os indicadores sociais são piores, os municípios vizinhos tendem a terem montantes de arrecadações baixos.

Para complementar esta análise, realizou-se o mapa de Cluster (aglomerados) gerado a partir do Índice Local de Associação Espacial - LISA (Figura 3). Observa-se que, entre os anos de 2006 a 2012, houve um aumento no número de municípios, principalmente nas regiões Central, Centro-Oeste e Sul de Minas, com padrão alto-alto (Teste LISA), evidenciando a melhoria social pretendida pela introdução de critérios diversos pela Lei 18.030/2009. Porém, o padrão baixo-baixo que, em 2006, estava em sua maioria nas Regiões Noroeste e do Rio Doce, em 2012 passou a ser distribuído nas regiões Norte e Jequitinhonha/Mucuri, demonstrando a concentração de municípios com baixo IMRS e vizinhança com baixa taxa de arrecadação de ICMS-E. 


\section{Reuna}

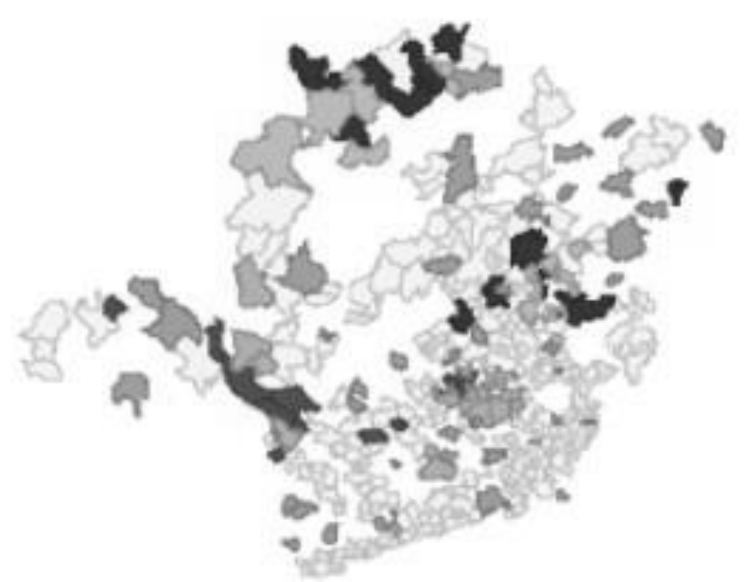

BILISA Cluster Map: icms_2006, ICMS_2006 w/ IMRS_2006 (99 perm)

$\square$ Not Significant (266)

High-High (14)

Low-Low (15)

$\square$ Low-High (27)

$\square$ High-Low (16)

$\square$ Neighborless (43)

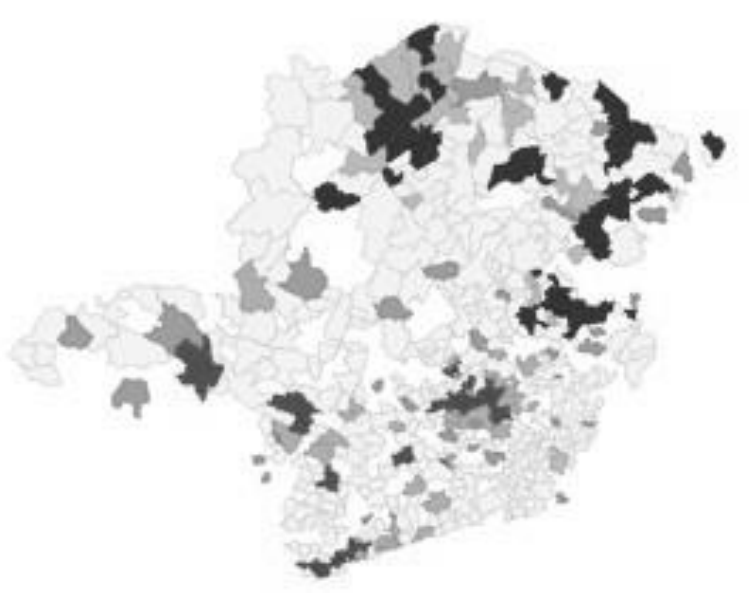

BiLISACluster Map: icms_2012, ICMS_2012 w/ IMRS_2012 (99 perm) $\square$ Not Significant (386)

$\square$ High-High (28)

Low-Low (37)

$\square$ Low-High (37)

$\square$ High-Low (24)

$\square$ Neighborless (33)

Figura 3 - Mapa Cluster do ICMS-E e do IMRS de 2006 e 2012 Fonte: Dados da pesquisa.

RELINA, Bela Horizonte - MG, Brasil, v.23, n.4, p.15-41, Dut. - Dez. 2018 - ISSN 2179-8834 
Vale destacar que a região Norte é peculiar nos resultados, uma vez que além de polos de padrão baixo-baixo (Teste LISA), apresenta concentrações de padrão alto-baixo (LISA), representando municípios com baixos IMRS's e valores mais altos de ICMS-E. Isso indica a influência do subcritério Mata Seca, introduzido na Lei para a determinação dos repasses. Também reflete que essas transferências fiscais não apresentaram relação direta com aspectos relacionados à qualidade de vida da população de municípios dessa região, medidos pelo IMRS, como meio ambiente, saneamento, saúde, entre outros.

\subsection{Repasse de ICMS-E e o PIB per capita}

Para avaliar a correlação entre os repasses de ICMS-E e o PIB per capita utilizou-se da metodologia de autocorrelação global bivariada (Moran) e uma matriz de pesos espaciais do tipo Rainha (Queen), a um nível de significância de 5\%.

Os resultados, apresentados na Tabela 3 , indicaram a inexistência de autocorrelação espacial positiva para o ano de 2008, e para os períodos de 2006, 2010 e 2012 houve a indicação de autocorrelação espacial positiva entre as variáveis, mas em níveis baixos para o índice de Moran. Estes valores evidenciam, apesar das significâncias nos testes, fragilidades nas autocorrelações entre os valores arrecadados de ICMS-E e o PIB per capita das localidades vizinhas.

Tabela 3 - Autocorrelação global bivariada (Moran) entre o PIB per capita e o ICMS-E, nos períodos de 2006, 2008, 2010 e 2012

\begin{tabular}{l|cc|c}
\hline \multicolumn{1}{c|}{ Variáveis } & I & z & p-value \\
\hline PIB per capita e ICMS-E-2006 & 0,0807 & 2,6728 & 0,013 \\
PIB per capita e ICMS-E-2008 & 0,0479 & 1,5128 & 0,071 \\
PIB per capita e ICMS-E-2010 & 0,0982 & 2,5591 & 0,016 \\
PIB per capita e ICMS-E-2012 & 0,0712 & 2,597 & 0,017 \\
\hline
\end{tabular}

Fonte: Dados da pesquisa.

Devido a estes valores mais baixos do Índice de Moran, o estudo adicionou observações sobre os padrões de agrupamentos dos dados e a sua evolução ao longo do tempo com o diagrama de dispersão de Moran (Figura 4). Percebeu-se, através da Figura 4, que os gráficos apresentaram valores dispersos nos quatros quadrantes, produzindo uma reta com uma pequena inclinação, a qual foi menor em 2012, corroborando com a baixa correlação espacial apresentada ao longo dos anos de estudo, o que reforça o princípio redistributivo da Lei18.030/2009. 

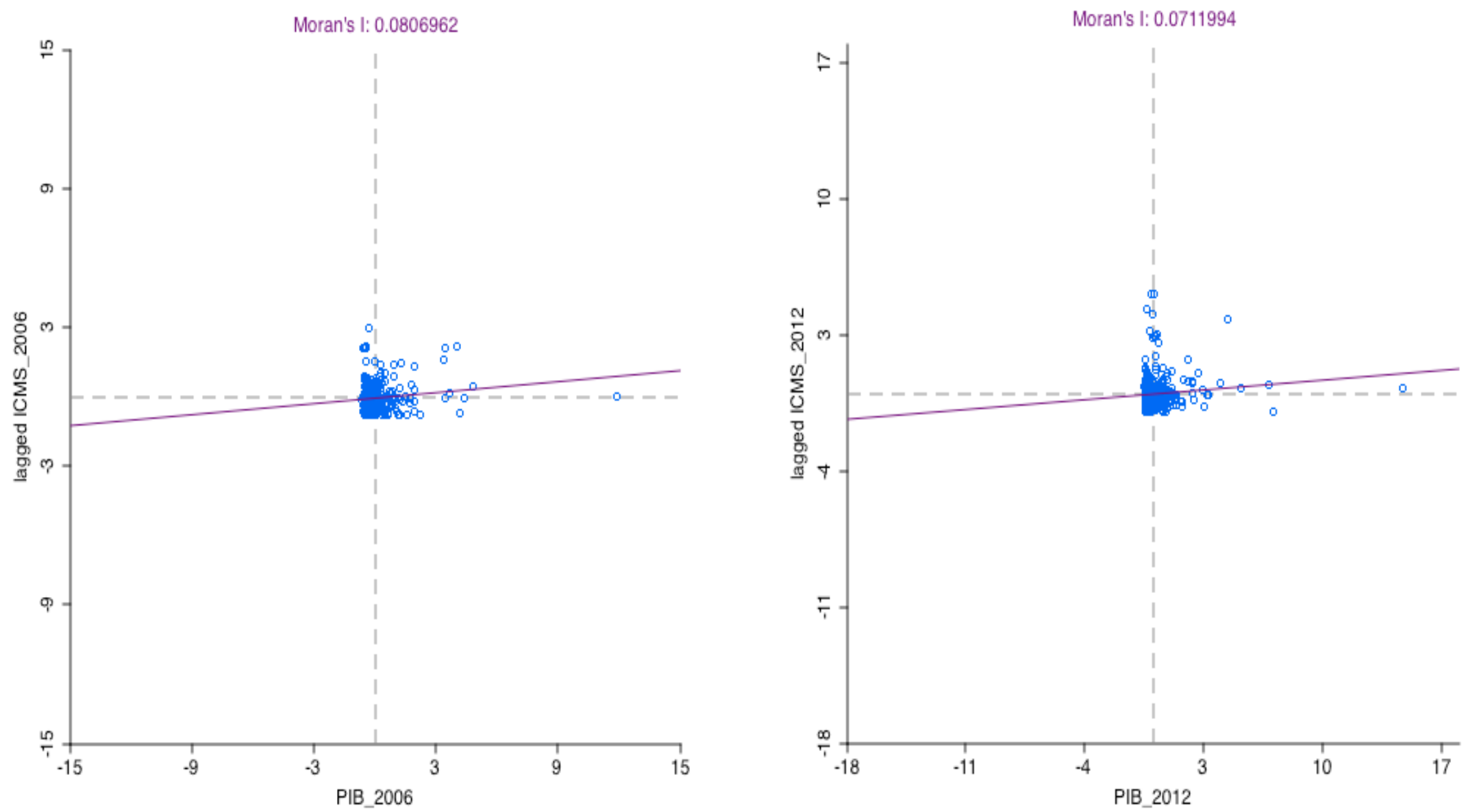

Figura 4 - Diagrama de dispersão de Moran bivariado do PIB per capita e do ICMS-E para os anos de 2006 e 2012 Fonte: Dados da pesquisa.

REUNA, Belo Horizonte - MG, Brasil, v.23, n.4, p.15-41, Dut. - Dez. 2018 - ISSN 2179-8834 
Para verificar a ocorrência de diferentes regimes de associação espacial, fezse uso do mapa de Cluster gerado a partir do Índice Local de Associação Espacial LISA, conforme Figura 5. Os resultados apresentaram diversas variações. Em 2006, o padrão alto-alto (Teste LISA) estava concentrado nas regiões do Alto Paranaíba e Triângulo Mineiro. Já em 2012 esse padrão passou a ficar concentrado, novamente, no Alto Paranaíba e mais intensamente na região Central, evidenciando a concentração de municípios com altos PIB's per capita e elevados valores de arrecadação do ICMS-E. Há de se destacar que a concentração de padrões alto-alto (LISA) ao longo dos anos de estudo não variou significativamente (em 2006, municípios nesse padrão, 3,67\%, e em 2012, 4\%).

O padrão baixo-baixo (Teste LISA) que, em 2006, estava em sua maioria nas regiões Norte e Jequitinhonha, com pequenos pontos na região Central, manteve as mesmas observações em 2012, mas em maior proporção.

Em 2006, os municípios recebedores de ICMS-E com padrão baixo-baixo (LISA) representavam 6,8\% e, em 2012, 8,4\%. Tal cenário reflete o aumento da concentração de municípios com baixos PIB's per capita e que possuem localidades vizinhas com menores arrecadações do ICMS-E.

Ressalta-se que o mapa Cluster de 2012 apresenta uma concentração do padrão alto-baixo (LISA) na região Norte, em substituição ao padrão baixo-baixo (LISA) observado em 2006. Esta situação aponta que municípios com altas arrecadações de ICMS-E possuem vizinhos com baixos PIB's per capita. Este fato pode ser explicado pelo aumento da arrecadação do iposto na região Norte, advindo da inclusão do subcritério Mata Seca que, uma vez ocorrido no ano de 2009, não provocou impactos relevantes na renda municipal em 2012. 


\section{Reuna}

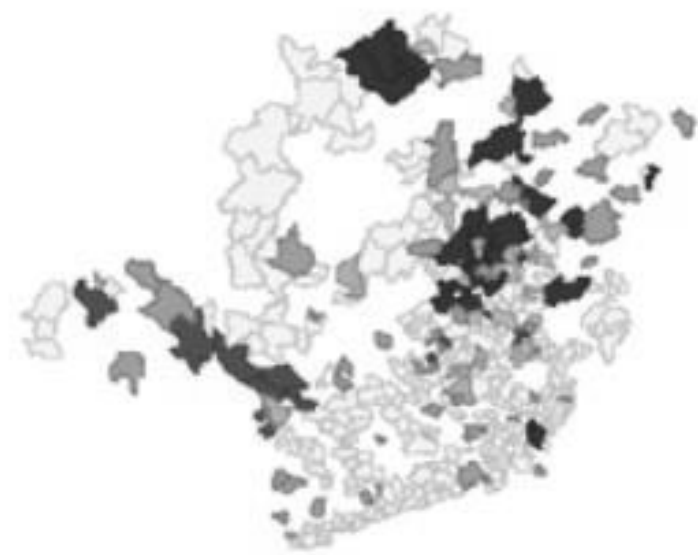

BiLISA Cluster Map: icms_2006, ICMS_2006 w/ PIB_2006 (99 perm)

$\square$ Not Significant (262)

High-High (14)

Low-Low (25)

Low-High (14)

High-Low (23)

Neighborless (43)

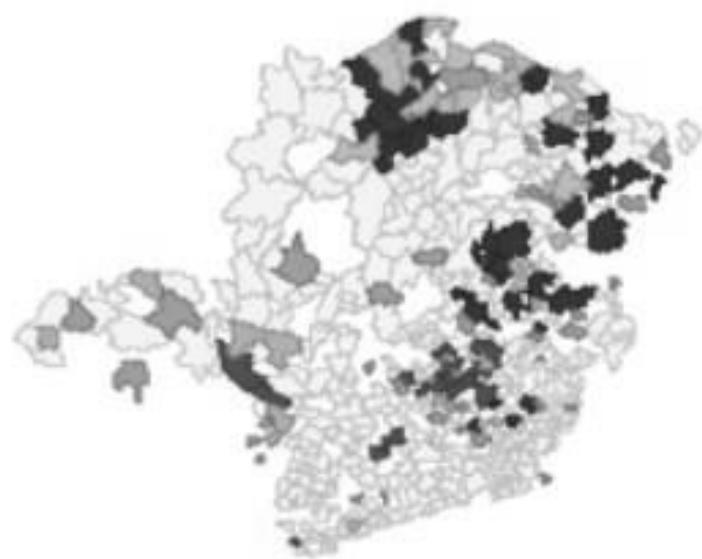

BLISA Cluster Nap: icms_2012, ICMS_2012 w/ PIB_2012 (99 perm) $\square$ Not Significant (402)

High-High (22)

Low-Low (46)

Low-High (14)

High-Low (28)

Neighborless (33)

Figura 5 - Mapa Cluster do ICMS-E e do PIB per capita de 2006 e 2012 Fonte: Dados da pesquisa.

REUNA, Belo Horizonte - MG, Brasil, v.23, n.4, p.15-41, Dut. - Dez. 2018 - ISSN 2179-8834 


\section{Considerações finais}

O ICMS-E foi implantado em Minas Gerais no ano de 1995 por meio da Lei n.․ 12.040/95 - Lei Robin Hood - que visava à redução das diferenças econômicas e sociais entre os municípios, incentivando a aplicação de recursos no meio ambiente (Unidades de Conservação, Saneamento Ambiental e Básico e Mata Seca).

Neste contexto, o presente estudo analisou se a distribuição espacial dos repasses financeiros do ICMS-E possuem influências no Índice Mineiro de Responsabilidade Social - IMRS e no Produto Interno Bruto (PIB) per capita. Para tanto, houve a utilização da AEDE, como contribuição para a literatura da área pública, uma vez que há uma possível existência de spillover espacial entre municípios vizinhos.

As análises indicaram que a arrecadação do ICMS-E apresenta relação espacial positiva, ou seja, municípios que exibem valores elevados de arrecadação do ICMS-E tendem a estar rodeados por vizinhos na mesma situação. Os municípios com arrecadação abaixo da média tendem a estar circunvizinhados por municípios com situações semelhantes. Estes resultados evidenciam um comportamento análogo entre municípios vizinhos quanto à adequação aos subcritérios do ICMS-E.

Além disso, é importante discorrer com estes resultados que, uma vez que as políticas nacionais e estaduais de proteção ao meio ambiente dependem do engajamento dos gestores dos municípios, verificou-se que as transferências fiscais, via ICMS-E, envolveu ao longo dos anos analisados um conjunto maior de municípios, demonstrando o seu papel incentivador e o efeito spillover.

Observou-se ainda que a arrecadação do imposto, ICMS-E, não se distribuiu uniformemente entre os anos de estudo e o seu padrão de distribuição anual não foi homogêneo entre os municípios mineiros. Assim, foram observadas regiões com arrecadações acima da média e outras abaixo. A região de planejamento que apresentou a maior alteração no número de municípios contemplados com o ICMS-E ao longo dos anos foi a Norte. Este cenário pode ser explicado pela introdução, na Lei 18.030/2009, do critério Mata Seca, que beneficiou quase exclusivamente essa região.

Os resultados da pesquisa também mostraram que a relação do ICMS-E com - IMRS tornou-se mais significativa ao longo dos períodos, evidenciando que os municípios com indicadores sociais mais elevados, estavam circunvizinhados por unidades municipais com arrecadações de ICMS acima da média. Estes resultados apontam que os esforços para a melhoria da qualidade de vida da população desses municípios, medida pelo IMRS, passaram a estar associados também ao atendimento de questões vinculadas à preservação do meio ambiente. Porém, foi encontrada a ampliação do número de municípios com baixo IMRS e pequenos valores de repasse via ICMS-E. Estes aumentos dos padrões baixo-baixo representam a presença de polos que não apresentaram os efeitos positivos da redistribuição tributária.

. Os resultados referentes as associações especiais entre o ICMS-E e o PIB per capita mostraram uma relação espacial positiva, pouco expressiva, apenas nos anos de 2006, 2010 e 2012.No entanto, essa autocorrelação espacial das variáveis 
reduziu de 2006 para 2012. Este cenário reflete as mudanças dos critérios para transferências aos municípios do ICMS em Minas Gerais, enfatizando os seus aspectos redistributivos, mesmo que a existência da baixa correlação possa indicar que a proporção de municípios mais ricos recebe as maiores cotas do imposto.

Destaca-se a necessidade de atuação do município para o recebimento do ICMS-E, medida que poderá beneficiar a população local e gerar externalidades positivas, uma vez que os resultados da preservação do meio ambiente não se restringem somente à dimensão local. No entanto, para abranger maior número de municípios, o governo de Minas Gerais deve constantemente analisar e adaptar os critérios de distribuição do ICMS, visto que há indícios nos resultados deste estudo que a força dos maiores municípios prevalece na arrecadação do ICMS e suas especificidades.

Apesar da limitação nos dados, principalmente do IMRS, o estudo utilizou uma metodologia inovadora, AEDE, para a Administração Pública, o que permitiu a investigação da Lei Robin Hood sob outra perspectiva. A observação de políticas públicas e seus efeitos espaciais são importantes para entender a sua amplitude e relação com territórios próximos.

Visando desenvolver esta área e fortalecer a literatura, há sugestões para estudos futuros. Inicialmente, sugere-se a utilização da econometria espacial que complementaria a AEDE. Segundo, aconselha-se a análise espacial mais restrita e qualitativa por regiões administrativas. Terceiro, sugere-se a utilização da análise espacial em outros critérios da Lei Robin Hood. Por fim, também há a indicação de investigações, sob a ótica da Teoria de Agência, se existem conflitos ou não entre as ações municipais para a Lei Robin Hood e os interesses do governo estadual.

\section{Referências}

ALMEIDA, E. Econometria Espacial Aplicada. Campinas: Alínea, 2012.

ALMEIDA, E. S.; HADDAD, E. A.; HEWINGS, G. J. D. The spatial pattern of crime in Minas Gerais: an exploratory analysis. Economia Aplicada, v. 9, n. 1, 2005.

ANSELIN, Luc. Spatial econometrics: methods and models. Boston: Kluwer Academic, 1988.

Exploratory spatial data analysis in a geocomputacional environment. In: Longley P. A.; Brooks; S. M.; MCDONNELL, R.; MACMILLIAN; B. Geocomputation a primer. Chichester: John Willey \& Sons Ltd, 1998, p.77-94.

ANSELIN, LUC; SYABRI, I.; KHO, Y. GeoDa: an introduction to spatial data analysis. [S.I.]: University of Illinois, 2003. (mimeo).

BALLEIRO, A. Direito tributário brasileiro. Rio de Janeiro: Forense, 2010.

BORGES, F. H.; TACHIBANA, W. K. A evolução da preocupação ambiental e seus reflexos no ambiente dos negócios: uma abordagem histórica. In: XXV Encontro Nacional de Engenharia de Produção, 25, 2005, Porto Alegre. Anais... Porto Alegre: Abepro-PUCRS, Nov./2005, p. 5235-5242. 
BRANDÃO, R. F. Incentivo Fiscal Ambiental: Parâmetros e Limites para sua Instituição à Luz da Constituição Federal de 1988. 2013. 267 f. Tese (Doutorado em Direito) - Faculdade de Direito da Universidade de São Paulo, São Paulo, SP, 2013.

BRASIL. Constituição (1988). Constituição da República Federativa do Brasil. 18.ed. Brasília, DF: Senado, 1988.

CASE, A., ROSEN, H. S.; HINES, J. R. Budget spillovers and fiscal policy interdependence: evidence from the states, Journal of Public Economics, $v 1$, n. 52, p. 285-307, 1993.

DA SILVA JÚNIOR, L.H.; SOBRAL, E.M.F. O ICMS Socioambiental de Pernambuco: Uma avaliação dos componentes socioeconômicos da política a partir do processo de Markov. Planejamento e Políticas Públicas, v. 1, n.42, p. 189-217, jan./jun. 2014.

DROSTE, N.; LIMA, G. R.; MAY, P. H.; RING,I. Municipal responses to ecological fiscal transfers in Brazil - a microeconometric panel data approach. Environmental Policy and Governance, v. 27, n. 4, p. 378-393, Jul./Aug. 2017.

DUARTE, L. C. B. A Politica Ambiental Internacional: Uma Introdução. Cena Internacional - Revista de Análise em Política Internacional, v. 6, n. 1, p. 4-12, jun. 2004.

EUCLYDES, A. C.P. Contradições da política ambiental por meio de incentivos financeiros: os casos do ICMS ecológico e da CFEM nos municípios do Quadrilátero Ferrífero (Minas Gerais, Brasil). Revista Árvore, v. 37, n. 6, p. 10831092, Dez. 2013.

FERNANDES, L. L.; COELHO, E. A. F.; FERNANDES, E. A.; LIMA, J. E. Compensação e incentivo à proteção ambiental: o caso do ICMS ecológico em Minas Gerais. Revista de Economia e Sociologia Rural, v. 1,v.49, n.3, jul./set. 2011.

FUNDAÇÃO JOÃO PINHEIRO. Manual Lei 18.030 - 2010. Disponível em: <http://www.fjp.mg.gov.br/robin-hood/index.php/leirobinhood/manual>. Acesso em: 25 ago. 2016.

HACK, E. As finalidades do tributo: como ele pode ser utilizado como instrumento de arrecadação e busca dos objetivos do Estado. ANIMA: Revista Eletrônica do Curso de Direito das Faculdades OPET, v. 3, n. 7, p. 135-153, jan/jun. 2012.

IBGE - Instituto Brasileiro de Geografia e Estatística. Pesquisa Nacional por Amostra de Domicílios Contínua, 2015. Disponível em: <http://www.ibge.gov.br/home/estatistica/pesquisas/pesquisa_resultados.php?id_pes quisa=149>. Acesso em: 10 dez. 2016.

IVERSEN, Carl. Política Fiscal em Países Subdesenvolvidos. Revista da Faculdade de Direito UFPR, v. 3, n. 0, p. 21-99, dez. 1955. 
KOLLNER, T.; SCHELSKE, O.; SEIDL, I. Integrating biodiversity into intergovernmental fiscal transfers based on cantonal benchmarking: a Swiss case study. Basic and Applied Ecology, v. 3, n. 4, p. 381-391, 2002.

LESAGE, J.; PACE, R. K. Introduction to spatial econometrics. New York: Champain \& Hall/CRC, 2009.

LIMA, C. Clube de Roma debate futuro do planeta há quatro décadas. Portal PUC-RJ digital. 16 de março de 2012. Disponível em: <http://puc-riodigital.com.pucrio.br/Texto/Meio-Ambiente/Clube-de-Roma-debate- futuro-do-planeta-ha-quatrodecadas-12080.html\#.VgfMp49Viko>. Acesso em: 27 set. 2016.

LOBO, Rogério Leite. Os atos de tributação interventivos no domínio econômico. Revista de Direito Administrativo, v. 232, n. 1, p. 29-52, Abr/Jun. 2003.

MARCONATO, Márcio. Análise Espacial da Pobreza nos Municípios Brasileiros no Ano de 2010. 2015. 100 f. Dissertação (Mestrado em Economia Regional) Centro de Estudos Sociais aplicados da Universidade Estadual de Londrina, Londrina, 2015.

MAY, P.H.; VEIGA NETO, F.; DENARDIN, V.; LOUREIRO, W. Using fiscal instruments to encourage conservation: municipal responses to the 'ecological' value-added tax in Paraná and Minas Gerais, Brazil. In: Pagiola, S., Bishop, J., Landell-Mills, N. (Eds.), Selling Forest Environmental Services: Market-based Mechanisms for Conservation and Development. Earthscan, London, 2002, p. 173-199.

NABAIS, J. C. Por uma liberdade com responsabilidade: Estudos sobre direitos e deveres fundamentais. Coimbra: Coimbra editora, 2007.

PASSOS, P. N. C. A Conferência de Estocolmo como Ponto de Partida para a Proteção Internacional do Meio Ambiente. Revista Direitos Fundamentais \& Democracia, v. 6, n. 6, p. 1-25, julho/dezembro. 2009.

PEROBELLI, F. S.; ALMEIDA, E. S.; ALVIM, M. I. S. A.; FERREIRA, P. G. C. Produtividade do setor agrícola brasileiro (1991-2003): uma análise espacial. Nova economia, v. 17, n. 1, p. 65-91, abril. 2007.

PIMENTEL, E. A.; HADDAD, E. A. Análise da distribuição espacial da renda no Estado de Minas Gerais: uma abordagem setorial. 2004. Disponível em: < http://www.econ.fea.usp.br/nereus/td/Nereus_02_04.pdf>. Acesso em: 11 out. 2016.

RING, I. Integrating local ecological services into intergovernmental fiscal transfers: the case of the ecological ICMS in Brazil. Science Direct Land Use Policy, v. 25, n. 4,p. 485-497, 2008.

RING, I. Ecological public functions and fiscal equalisation at the local level in Germany. Ecological Economics, v. 42, n. 3,p.415-427,2002. 
SAUQUET, A.; MARCHAND, S.; FÉRES, J. Protected areas, local governments, and strategic interactions: the case of the ICMS-Ecológico in the Brazilian state of Paraná. Ecological Economics, v. 107, n. 1, p. 249-258, 2014.

SCAFF, F. F.; TUPIASSU, L. V. C. Tributação e políticas públicas: O ICMS ecológico. Hiléia - Revista de Direito Ambiental da Amazônia, v. 2, n. 2, janeirojunho 2004.

SCAFF, F. F.; TUPIASSU, L. V. C. Tributação e políticas públicas: o ICMS ecológico. In: TORRES, H. T. (Org.) Direito tributário ambiental. São Paulo: Malheiros, 2005. $894 \mathrm{f}$.

SCHOUERI, L. E. Normas tributárias indutoras e intervenção econômica. Rio de Janeiro: Forense, 2005.

THE NATURE CONSERVANCY. ICMS Ecológico. Disponível em: <http://www.icmsecologico.org.br/site/index.php?option=com_content\&view=article\&i $\mathrm{d}=53 \&$ Itemid=60\#go $>$. Acesso em: 29 ago .2016.

TORRES, R. L. A ideia de liberdade no Estado patrimonial e no Estado fiscal, Rio de Janeiro: Renovar, 1991.

VEIGA NETO, F. C. Análise de incentivos econômicos nas políticas públicas para o meio ambiente - O caso do ICMS Ecológico em Minas Gerais. 2000. 161 f. Dissertação (Mestrado em Desenvolvimento, Agricultura e Sociedade) Universidade Federal Rural do Rio de Janeiro, Rio de Janeiro, 2000. 